\title{
Response to comment on: Meier JJ, Lin JC, Butler AE, Galasso R, Martinez DS, Butler PC (2006) Direct evidence of attempted beta cell regeneration in an 89-year-old patient with recent-onset type 1 diabetes. Diabetologia 49:1838-1844
}

\author{
J. J. Meier • J. C. Lin • A. E. Butler • R. Galasso • \\ D. S. Martinez • P. C. Butler \\ Received: 24 July 2006 / Accepted: 25 July 2006 / Published online: 14 September 2006 \\ (C) Springer-Verlag 2006
}

\section{To the Editor:}

We thank Dr Zhao for his interest in our recent publication showing attempted beta cell regeneration in an 89-year-old patient with recent-onset type 1 diabetes [1,2]. Zhao argues that a nucleus co-stained for Ki67 (red) and 4,6-diamidino2-phenylindole (DAPI) (blue) should show a purple colour. The colour shading of merged images depends on the intensity of each individual colour channel, and in the present case the light blue nuclear staining was overshadowed by the intense red Ki67 labelling. To illustrate this we have provided higher power magnifications of the same images showing specific staining for insulin, Ki67 and nuclei, both as single colour channels and as merged colour images (Fig. 1). These figures demonstrate that Ki67 was co-localised with the nuclear marker DAPI and surrounded by cytoplasmic insulin labelling. Zhao also suggests that in his long-standing experience, elongated nuclei, such as the one stained for Ki67 in Fig. 5a of our article, were suggestive of stromal fibroblasts. Again, we would like to point to the high-power images, which clearly show co-expression of Ki67 and DAPI as well as cytoplasmic insulin labelling. In fact, any oval-shaped nucleus can easily appear elongated in cross-section, and elongation and polarisation of nuclear chromatin spindles are well-recognised characteristics of mitotic cell divisions

J. J. Meier • A. E. Butler • R. Galasso $\cdot$ P. C. Butler $(\bowtie)$

Larry Hillblom Islet Research Center,

UCLA David Geffen School of Medicine,

24-130 Warren Hall, 900 Veteran Avenue,

Los Angeles, CA 90095-7073, USA

e-mail: pbutler@mednet.ucla.edu

J. C. Lin · D. S. Martinez

Division of Endocrinology, Diabetes and Hypertension,

UCLA David Geffen School of Medicine,

Los Angeles, CA, USA
[3]. Furthermore, a number of studies have demonstrated that the quantitative morphometric assessment of specific proliferation markers such as Ki67 is often superior to the classical histopathological evaluation of tissue sections, which suffers from considerable interobserver variability [4-6].

We acknowledge the possibility that a small subset of fibroblasts and vascular smooth muscle cells might co-stain with the antibodies against CD68, even though the higher expression rates in this case compared with normal human pancreas seems very consistent with an inflammatory response. Nevertheless, the extensive lymphocytic infiltration of the islets shown by specific staining for the $\mathrm{T}$ lymphocyte markers CD3, CD4 and CD8 clearly suggests a florid insulitis in this case [2].

Regarding the potential impact of labelling diffusion artefacts, this limitation may apply to the analysis of two or more markers expressed in the same subcellular compartment. In this case, however, beta cell apoptosis was assessed based on nuclear terminal deoxynucleotidyl transferase-mediated dUTP-biotin nick-end labelling (TUNEL) staining in cells fully surrounded by an insulinpositive cytoplasm. The argument that TUNEL staining in beta cells might represent insulin-positive cells with phagocytotic bodies seems invalid, since such particles would be expected in the cytoplasm rather than in the nuclear compartment $[7,8]$. Furthermore, we and others have previously validated the use of TUNEL staining as a marker of apoptosis in human pancreas by comparison with staining for cleaved caspase- $3[9,10]$. In the case of our 89year-old patient, ongoing islet cell destruction was also apparent from the large areas of nuclear fragmentation, as shown in Fig. 5a (centre) and b (bottom) of the article [2].

In conclusion, the nuclear-specific staining of the established proliferation marker Ki67 within islet beta cells 

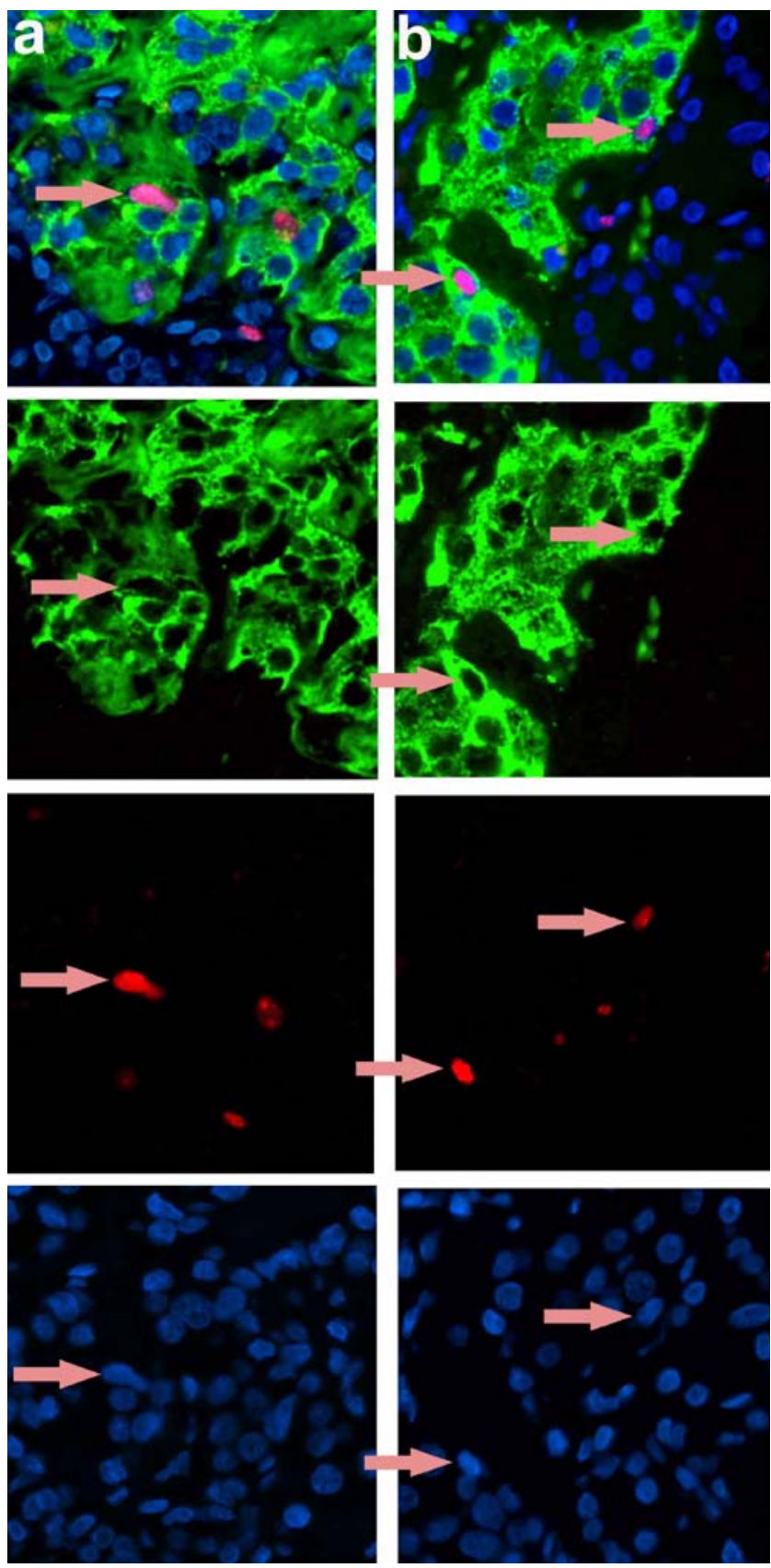

Fig. 1 Pancreatic sections from an 89-year-old patient presenting with recent-onset type 1 diabetes stained for insulin (green), Ki67 (red) and DAPI (blue), showing multiple replicating beta cells (arrows). The images are parts of Fig. 5 of the Original Article [2] reproduced at higher magnification. Figures are shown as merged colour images and individually for each colour channel clearly demonstrates the presence of beta cell replication in this case of newly diagnosed type 1 diabetes, in contrast to previously studied patients with long-standing type 1 and type 2 diabetes examined by our group with the same method [9-11]. The massive lymphocytic infiltration in combination with cellular debris, nuclear TUNEL staining and nuclear fragmentation by DAPI staining leave little doubt that immune-related beta cell apoptosis was indeed the mechanism underlying the $\sim 70-80 \%$ loss of beta cell mass in this islet autoantibody-positive case of recent-onset diabetes.

\section{References}

1. Zhao H-L (2006) Comment on: Meier JJ, Lin JC, Butler AE, Galasso R, Martinez DS, Butler PC (2006) Direct evidence of attempted beta cell recognition in an 89 -year-old patient with recent onset type 1 diabetes. Diabetologia. DOI 10.1007/s00125006-0411-4

2. Meier JJ, Lin JC, Butler AE, Galasso R, Martinez DS, Butler PC (2006) Direct evidence of attempted beta cell regeneration in an 89 -year-old patient with recent-onset type 1 diabetes. Diabetologia 49:1838-1844

3. Pickett-Heaps JD, Tippit DH (1978) The diatom spindle in perspective. Cell 14:455-467

4. Lorinc E, Jakobsson B, Landberg G, Veress B (2005) Ki67 and p53 immunohistochemistry reduces interobserver variation in assessment of Barrett's oesophagus. Histopathology 46:642-648

5. Pich A, Chiusa L, Navone R (2004) Prognostic relevance of cell proliferation in head and neck tumors. Ann Oncol 15: 1319-1329

6. Brown DC, Gatter KC (2002) Ki67 protein: the immaculate deception? Histopathology 40:2-11

7. Shui YB, Sasaki H, Pan JH, Hata I et al (2000) Morphological observation on cell death and phagocytosis induced by ultraviolet irradiation in a cultured human lens epithelial cell line. Exp Eye Res 71:609-618

8. de Almeida CJ, Linden R (2005) Phagocytosis of apoptotic cells: a matter of balance. Cell Mol Life Sci 62:1532-1546

9. Meier JJ, Bhushan A, Butler AE, Rizza RA, Butler PC (2005) Sustained beta cell apoptosis in patients with long-standing type 1 diabetes: indirect evidence for islet regeneration? Diabetologia 48:2221-2228

10. Maedler K, Fontana A, Ris F et al (2002) FLIP switches Fasmediated glucose signaling in human pancreatic beta cells from apoptosis to cell replication. Proc Natl Acad Sci USA 99:82368241

11. Butler AE, Janson J, Bonner-Weir S, Ritzel R, Rizza RA, Butler PC (2003) Beta-cell deficit and increased beta-cell apoptosis in humans with type 2 diabetes. Diabetes 52:102-110 